\title{
Diffusion Tensor Imaging in chronically shunted patients
}

\author{
Kristy Tan ${ }^{1 *}$, Adam L Sandler ${ }^{2}$, Avital Meiri', Rick Abbott ${ }^{2}$, James T Goodrich², Asif K Suri, Michael L Lipton, \\ Mark E Wagshul ${ }^{1}$ \\ From Hydrocephalus 2015 \\ Banff, Canada. 18-21 September 2015
}

\section{Introduction}

Chronically shunted patients with functioning shunts are often characterized as having slit or smaller than normal ventricles and chronic headaches. In this study, we used Diffusion Tensor Imaging (DTI) to quantitatively analyze the directionality of water diffusion in the internal capsule (IC) and the corpus callosum (CC) in these patients which have been shown to be affected in untreated hydrocephalus patients [1].

\section{Methods}

Shunt-dependent patients who developed hydrocephalus as infants were selected. Preliminary results from 17 patients who suffer from chronic headaches (excluding patients with abnormally large ventricles) are shown in comparison to age and gender matched controls. DTI data was acquired using a single-shot EPI sequence with TE/ $\mathrm{TR}=69 / 10000 \mathrm{~ms}$, voxel size $=2 \mathrm{~mm} \times 2 \mathrm{~mm} \times 2 \mathrm{~mm}$, $\max$ $\mathrm{b}$-factor $=800$, num. of directions $=32$. White matter ROIs were manually drawn on high-resolution T1-weighted images with the aid of fractional anisotropy (FA) maps to locate the internal capsule (IC) (right and left, anterior and posterior limbs), genu and splenium of the corpus callosum $(C C)$ and were verified by a neuroradiologist.

\section{Results}

A statistically significant decrease (student t-test, $\mathrm{p}<0.05$ ) in FA was found in the patient group compared to the controls in the right posterior $(\mathrm{FA}=0.61$ vs 0.65 , $\mathrm{p}=0.0045)$, left posterior $(\mathrm{FA}=0.61$ vs $0.66, \mathrm{p}<0.001)$ and left anterior IC ( $F A=0.56$ vs $0.63, p=0.0031)$ as well as the splenium of the CC (FA=0.69 vs $0.80, \mathrm{p}<0.001)$. No

\footnotetext{
* Correspondence: kristy.tan@einstein.yu.edu

${ }^{1}$ Albert Einstein College of Medicine, USA

Full list of author information is available at the end of the article
}

correlations were found between ventricular volumes with the DTI parameters.

\section{Conclusions}

This study is the first to use DTI to study chronically shunted patients and shows evidence of white matter degradation based on decreases in FA in patients compared to controls. Previous studies have shown increased FA values in the IC and a decrease in the CC of patients and hypothesized that it was due to an increase of mechanical compression whilst others have hypothesized that a decrease in FA indicated secondary irreversible, degenerative changes [1-3]. These studies were performed on younger patients pre-treatment who usually have enlarged ventricles and we hypothesize that this may be the source of the difference coupled with the chronic shunt dependence within our patient group.

\section{Authors' details}

${ }^{1}$ Albert Einstein College of Medicine, USA. ${ }^{2}$ Department of Neurological Surgery, Albert Einstein College of Medicine/Children's Hospital at Montefiore, Bronx, NY, USA.

\section{Published: 18 September 2015}

\section{References}

1. Assaf $Y$, et al: Diffusion tensor imaging in hydrocephalus: initial experience. American journal of neuroradiology 2006, 27(8):1717-1724.

2. Ben-Sira $L$, et al: Clinical benefits of diffusion tensor imaging in hydrocephalus. Journal of Neurosurgery: Pediatrics 2015, 1-8.

3. Hoza D, et al: DTI-MRI biomarkers in the search for normal pressure hydrocephalus aetiology: a review. Neurosurgical review 2015, 38(2):239-244.

4. Bilston L, Tan K: Measurement of Passive Skeletal Muscle Mechanical Properties In Vivo: Recent Progress, Clinical Applications, and Remaining Challenges. Annals of Biomedical Engineering 2015, 43(2):261-273, doi: 10.1007/s10439-014-1186-2.

5. Farnoush A, Tan K, Juge L, Bilston L, Cheng S: The effects of endoscopic third ventriculostomy on cerebrospinal fluid pressure in the cerebral ventricles. Journal of Clinical Neuroscience 2015. 
6. Hatt A, Cheng S, Tan K, Sinkus R, Bilston L: MR Elastography Can Be Used to Measure Brain Stiffness Changes as a Result of Altered Cranial Venous Drainage During Jugular Compression. American Journal of Neuroradiology 2015.

7. Tan $K$, Cheng $S$, Juge L, Bilston L E: Characterising soft tissues under large amplitude oscillatory shear and combined loading. Journal of Biomechanics 2013, 46(6):1060-1066, doi: 10.1016/j.jbiomech.2013.01.028.

8. Cheng S, Tan K, Bilston L E: The effects of the interthalamic adhesion position on cerebrospinal fluid dynamics in the cerebral ventricles. Journal of Biomechanics 2010, 43(3):579-582.

doi:10.1186/2045-8118-12-S1-031

Cite this article as: Tan et al: Diffusion Tensor Imaging in chronically shunted patients. Fluids and Barriers of the CNS 2015 12(Suppl 1):O31.

\section{Submit your next manuscript to BioMed Central} and take full advantage of:

- Convenient online submission

- Thorough peer review

- No space constraints or color figure charges

- Immediate publication on acceptance

- Inclusion in PubMed, CAS, Scopus and Google Scholar

- Research which is freely available for redistribution

Submit your manuscript at www.biomedcentral.com/submit 